At the same time, the use of anti-B-cell drugs in combination therapy resulted in a significant decrease of the vaccinal response

Disclosure of Interests: None declared

DOI: 10.1136/annrheumdis-2019-eular.3646

\section{FRI0213 RANDOMIZED PLACEBO CONTROLLED TRIAL OF ABATACEPT FOR NON-ORGAN THREATENING SYSTEMIC LUPUS WITH BACKGROUND MEDICATIONS WITHDRAWN}

Aikaterini Thanou $^{1}$, Cristina Arriens ${ }^{1}$, Teresa Aberle ${ }^{1}$, Eliza Chakravary ${ }^{1}$, Samera Vaseer ${ }^{2}$, Joe Rawdon ${ }^{1}$, Judith A. James ${ }^{1}$, Joan Merrill ${ }^{1}{ }^{1}$ Oklahoma Medical Research Foundation, Oklahoma City, United States of America; ${ }^{2}$ The University of Oklahoma Health Sciences Center, Oklahoma City, United States of America

Background: Abatacept (ABA) is a fusion protein of the extracellular domain of CTLA4 and the Fc domain of human IgG1, constructed to inhibit $B / T$ cell co-stimulation. Previous studies of $A B A$ in lupus failed to show benefit in overall disease activity, but improvement in arthritis was suggested.

Objectives: This 6-month randomized, double-blind, placebo-controlled (PBO) study withdrew background medications to facilitate the assessment of $A B A$ in patients with SLE arthritis.

Methods: Patients were entered with moderate to severe arthritis [BILAG $A$ or $B$ with $\geq 3$ swollen and $\geq 3$ tender joints (28 joint count)]. All DMARDs except prednisone (up to $20 \mathrm{mg}$ daily) were withdrawn by baseline and patients were randomized $1: 1$ to weekly SC ABA or PBO. One or more DepoMedrol injections ( $\leq 320 \mathrm{mg}$ total) was allowed by end of Month 2. Additional steroids or immune suppressants (IMS) at any time, and transition to open label $\mathrm{ABA}$ at Month 3 or later, were allowed, but designated non-response. The primary endpoint was BICLA response at Month 6 compared to screening. Secondary objectives included SRI-4, SLEDAI 4-point improvement, SLEDAI arthritis resolution, BILAG A/B musculoskeletal (MSK) improvement, as well as low disease activity defined by either SLEDAI 2 or Lupus Low Disease Activity State (LLDAS) at Month 6. Flares were evaluated by the modified SELENA-SLEDAI flare index (1) in patients followed after baseline.

Results: 66 patients were randomized and received at least one dose of the study drug, $31 \mathrm{ABA}$ and 35 PBO. 7 withdrew prior to Month 6. Placebo response rates were lower than in most SLE trials, but no primary or secondary endpoints were met, see table (Fischer's exact test).

\begin{tabular}{lccc}
\hline & ABA $(\mathbf{n}=\mathbf{3 1})$ & PBO $(\mathbf{n}=\mathbf{3 5})$ & p value \\
\hline BICLA & $8(26 \%)$ & $8(23 \%)$ & $>0.999$ \\
SRI-4 & $9(29 \%)$ & $8(23 \%)$ & 0.587 \\
SLEDAI 4-point improvement & $9(29 \%)$ & $8(23 \%)$ & 0.587 \\
SLEDAI arthritis improvement & $9(29 \%)$ & $8(23 \%)$ & 0.587 \\
BILAG A/B MSK improvement & $9(29 \%)$ & $8(23 \%)$ & 0.587 \\
SLEDAI 2 & $8(26 \%)$ & $7(20 \%)$ & 0.769 \\
LLDAS & $6(19 \%)$ & $8(23 \%)$ & 0.772 \\
\hline
\end{tabular}

Flares were evaluable in 64 patients (31 on ABA, 33 on PBO). 14 (45\%) patients on $\mathrm{ABA}$ vs. $18(55 \%)$ on $\mathrm{PBO}$ had a moderate/severe flare by Month 6. 22 (71\%) patients on ABA vs. $23(70 \%)$ on PBO experienced flare or treatment failure (early drop off or off protocol steroids or IMS) by Month 6 . Rates of flare and treatment failure by Month 6 did not differ between groups (Log-Rank test, $p=0.688$ and $p=0.631$, respectively). The safety profile of $A B A$ was consistent with known effects of the treatment.

Conclusion: ABA did not demonstrate improvement vs placebo in controlling disease activity or flare in SLE patients in a protocol that mandated IMS withdrawal. Placebo response rates of $\leq 23 \%$ support the validity of these results. Since some evidence suggests potential efficacy of ABA for certain biologic subsets of SLE (2), immunophenotyping may prove helpful.

\section{REFERENCES:}

[1] Thanou A, Chakravarty E, James JA, Merrill JT. Rheumatology (Oxford) 2014;53(12):2175-81.

[2] Bandyopadhyay S, Connolly SE, Jabado O, Ye J, Kelly S, Maldonado MA, Westhovens R, Nash P, Merrill JT, Townsend RM. Lupus Sci Med. 20174 (1): e000206.

Disclosure of Interests: Aikaterini Thanou Grant/research support from: Bristol-Myers Squibb, Consultant for: Neovacs, Cristina Arriens Grant/ research support from: Bristol-Myers Squibb, GSK/HGS, Consultant for:
GSK, AstraZeneca, Teresa Aberle: None declared, Eliza Chakravary: None declared, Samera Vaseer: None declared, Joe Rawdon: None declared, Judith A. James: None declared, Joan Merrill Grant/research support from: Genentech, UCB, GSK, EMD Serono, Pfizer, Celgene, Exagen, Bristol Myers Squibb, Medimmune/Astra Zeneca, Lilly, Amgen, Xen cor, Neovacs, Consultant for: Genentech, UCB, GSK, EMD Serono, Pfizer, RemeGen, Celgene, Exagen, Bristol Myers Squibb, Medimmune/ Astra Zeneca, Lilly, Immupharma, Amgen, Janssen, Sanofi, Neovacs, Anthera, Speakers bureau: UCB, GSK, EMD Serono, Bristol Myers Squibb, Medimmune/Astra Zeneca, Janssen

DOI: 10.1136/annrheumdis-2019-eular.2526

\section{FRI0214 EFFICACY OF RITUXIMAB AND CYCLOPHOSPHAMIDE TREATMENT IN PATIENTS WITH PRIMARY SJOGREN'S SYNDROME AND PAROTID GLAND MALT LYMPHOMA}

Anna Torgashina, Bogdan Chalcev, Evgeniya Sokol, Vladimir Vasiliev. Nasonova Research Institute of Rheumatology, Moscow, Russian Federation

Background: Mucosa-associated lymphoid tissue (MALT) lymphoma occurred in a higher frequency and at an earlier age in primary Sjögren's syndrome (pSS) than reported for MALT lymphoma in the general population. The optimal treatment of MALT lymphoma in pSS has not been defined.

Objectives: to analyze retrospectively the long-term clinical course of pSS in patients with MALT lymphoma.

Methods: 63 SS patients with MALT lymphoma were retrieved from our pSS database. Most of the 63 pSS-lymphoma patients were female $(n=60 ; 95 \%)$. pSS was diagnosed at a mean age of 51 (43-58) years and lymphoma at a mean of $7(2-10)$ years later. Total mean follow-up was 5 years (2-8). 14 patients received immunomodulator agents for SS before the development of lymphoma (low doses of prednisone - 8 patients, chlorambucil - 7, cyclophosphamide - 3 patients). In 43 patients, the diagnosis of SS and MALT - lymphoma were established simultaneously. Clinical features and treatment outcome of MALT - lymphoma as well as SS activity was evaluated.

All patients had features of autoimmune disease (ANA-100\%, RF-90\%, anti-Ro or/and anti-La antinuclear antibodies-94\%) and met the diagnostic criteria of the Association of Rheumatologists of Russia for primary Sjogren's syndrome: salivary gland involvement (stimulated parotid flow rate < $2,5 \mathrm{ml}$ in $5 \mathrm{~min}$, parotid sialography showing the presence of diffuse punctuate or globular shadows with a diameter > $1 \mathrm{~mm}$., histopathology: a focus score $>2$ per $4 \mathrm{~mm} 2$ in minor salivary gland biopsy), keratoconjunctivitis sicca (stimulated Schirmer's test $<10 \mathrm{~mm}$ in $5 \mathrm{~min}$, tear break-up time $<10$ seconds, rose Bengal test or fluorescent test $>1+$ ), presence of abnormal concentrations of at least one of the serum autoantibodies (anti-Ro, anti-La, antinuclear antibodies, IgM-rheumatoid factor). The histologic and immunohistochemical diagnosis of lymphoma was performed with B-cell clonality determination in salivary gland tissue.

Patients were treated with RTX (25 patients) or $\mathrm{RTX}+\mathrm{CPH}$ (38 patients). Patients received $2 \mathrm{lg}$ intravenous infusions of RTX 2 weeks apart, then $375 \mathrm{mg}$ every 3 months for 2 years. Cyclophosphamide $1000 \mathrm{mg}$ was administered every two weeks for a period of 12 weeks.

Results: MALT lymphoma was localized in parotid glands in 60 cases, submandibular salivary glands - in 2 cases, lacrimal gland - in 1 case Eleven patients showed systemic features (7-purpura, 1-peripheral neuropathy, 3 - nephritis). Blood serum and urine examination revealed monoclonal secretion in 16/56 patients (7-lgMk, 4-lgGk and IgG, 2-lgAk and 3 - BJk). Nineteen of 56 (34\%) patients had cryoglobulinaemia.

After follow-up of 24 mo, complete clinical remission (CR) of MALT lymphoma (normalization of salivary gland size, disappearance of lymphadenopathy and cytopenia) was obtained in $25(72 \%)$ in the group of RTX and $35(92 \%)$ in the group of $\mathrm{RTX}+\mathrm{CPH}(\mathrm{p}=0.05)$. An incision biopsy of the parotid gland before and after therapy was made in 21 patients. Complete disappearance of histological pattern of MALT lymphoma was shown in $50 \%$ of the RTX treated patients and in $66 \%$ patients with combined therapy. B-cell clonality in parotid glands disappeared in $3 / 5$ cases after RTX monotherapy and in $1 / 4$ cases after RTX with CPH therapy. Cryoglobulinaemia disappeared in $33 \%$ patients in group of RTX and $46 \%$ in group of $\mathrm{RTX}+\mathrm{CPH}(\mathrm{p}=0.6)$.

Conclusion: Complete clinical remission of the lymphomas was achieved significantly more often in the group treated with RTX plus cytostatic agent in comparison with patients who had RTX monotherapy.

Disclosure of Interests: None declared

DOI: 10.1136/annrheumdis-2019-eular.8251 